\title{
La servucción y su importancia en los modelos de negocios actuales
}

\section{Servucción and its importance in current business models}

María Auxiliadora Guerrero Bejarano, MBA

Universidad internacional del Ecuador, Ecuador

Karen Guiseell Solís Vera

Universidad internacional del Ecuador, Ecuador

Daniel Ricardo Silva Siu, Msc

Universidad ESAN, Perú

Autor para correspondencia: maguerrerobe@uide.edu.ec,dsilva@pobox.com, karengsolis@gmail.com

Fecha de recepción: 27 de Mayo de 2017 - Fecha de aceptación: 10 de Mayo de 2017

\section{Resumen}

Por algún tiempo, se discute la importancia de la lealtad de los clientes para las empresas, y lo difícil que es conseguirla, mucho más en mercados emergentes, como, dónde la mayoría de los consumidores por su nivel adquisitivo está buscando ofertas y beneficios adicionales por el menor precio posible, en ocasiones sacrificando calidad, este análisis teórico y descriptivo permite resaltar la importancia de la logística detrás del servicio, su planificación y control para obtener mejores resultados en el objetivo principal de las empresas de servicio, la fidelización de los clientes.

Palabras clave: lealtad; calidad; importancia logística

\begin{abstract}
For some time, the importance of customer loyalty for business is discussed, and how difficult it is to achieve it, much more in emerging markets, such as where most consumers by purchasing power are looking for offers and additional benefits for the lowest possible price, sometimes sacrificing quality, this theoretical and descriptive analysis allows to highlight the importance of logistics behind the service, its planning and control to obtain better results in the main objective of service companies, customer loyalty.
\end{abstract}

Key words: loyalty; quality; logistic importance 


\section{Introducción}

Sin duda alguna el servicio al cliente se ha convertido en una fuente de valor agregado para todo tipo de empresas desde hace algunos años, mucho más desde que la forma en la que los clientes consumen hoy en día. Los consumidores actuales buscan ansiosamente por experiencias más allá de la satisfacción que el producto puede entregarle, actualmente y se podría afirmar que desde siempre los clientes exigen y prefieren productos y servicios que le garanticen conseguir cubrir sus necesidades y obtener su imagen de sujeto ideal esperado. En el florecimiento de la era de las industrial, el enfoque que mostraban las empresas siempre fue masificar su producción descuidando totalmente el servicio al cliente, esa calidad en el servicio que ahora resulta una de las bases que cimientan una empresa exitosa. (Lovelock, Carrion, Huete, Reynoso, \& D'Andrea, 2004)

En el Ecuador el 40,8\% de las empresas son de servicios, a este porcentaje podría sumarse el 36,5\% de empresas que se dedican al comercio, donde el servicio es parte integral de su actividad (INEC, 2014). El turismo receptor significa el $70 \%$ de las exportaciones de servicios (Falconí, 2015). En este país no existe a la fecha un estudio que explique o intente explicar el por qué algunas empresas tienen más éxito que otras en relación a su desempeño. El Ecuador al igual que otros países de América Latina va adaptándose a los cambios que la tecnología y la globalización provocan, por esta razón es importante conocer si la empresa ecuatoriana tiene comportamientos similares a las empresas de otras naciones.(Falconí, 2015)

En una economía de mercado, cada vez más competitiva y centrada en el cliente, las empresas de servicios se ven forzadas a proporcionar servicios de alta calidad, que les permitan obtener clientes satisfechos, para que estos recompren sus servicios y puedan obtener mayores niveles de rentabilidad. Para este tipo de empresas la prestación del servicio se vuelve vital, por lo que el papel de los empleados de primera línea es indiscutiblemente fundamental para la obtención de los resultados, (Pantouvakis \& Bouranta, 2013).

En el Ecuador, de acuerdo con datos oficinales, la balanza de servicios ha sido tradicionalmente negativa, en el 2014 en 1220 millones de dólares, el sector servicios aún es considerado desconocido por no tener estadísticas oficiales pese a aportar el $60 \%$ en el PIB (Falconí, 2015), actualmente este sector genera 1,9 millones de empleos en el país (Telégrafo, 2015) y las empresas de servicio representan el 40,8 \% del total de las empresas del país (INEC, 2014); a pesar de esto, los servicios en el Ecuador aún son ineficientes, lo que no permite aprovechar ventajas de acuerdos comerciales, de acuerdo con Falconí, coordinador técnico de negociaciones comerciales del ministerio de comercio exterior del Ecuador, en un mundo interrelacionado, postergaría el futuro del país (2015); un análisis realizado por el instituto de estudios económicos de la Universidad Técnica Particular de Loja, demuestra el desarrollo del sector en el país, pero destaca la baja productividad presente en el mismo (Ordoñez, 2011).

\section{Empresas de Servicio}

El sector de los servicios en todo el mundo, atraviesa por un período de cambio que podría considerarse revolucionario, debido a que la formas de hacer los negocios que nos eran familiares siguen cambiando de dirección continuamente vemos que los avances recientes en los servicios transforman nuestra manera de vivir y de trabajar. Con mayor frecuencia encontramos 
nuevos lanzamientos y nuevas formas de satisfacer las necesidades actuales e incluso algunas que resultan inimaginables, de la misma forma ocurre en los servicios dirigidos a los clientes corporativos. Aunque muchas nuevas empresas de servicios fracasan, algunas logran el éxito, en ocasiones de manera espectacular. Muchas compañías establecidas por largo tiempo también fracasan o se fusionan y dejan de existir; pero otras progresan debido a que consideran constantemente la manera de hacer sus negocios, buscando formas innovadoras de servir mejor a los clientes y aprovechando los adelantos recientes en la tecnología (Lovelock et al., 2004)

"Un servicio es un acto o desempeño que ofrece una parte a otra. Aunque el proceso puede estar vinculado a un producto físico, el desempeño es en esencia intangible y, por lo general, no da como resultado la propiedad de ninguno de los factores de producción. Los servicios son actividades económicas que crean valor y proporcionan beneficios a los clientes en tiempos y lugares específicos como resultado de producir un cambio deseado en (o a favor de) el receptor del servicio." (Lovelock et al., 2004)

Una compañía que ingresa al juego de seducción de sus clientes mediante un buen servicio debe procurar mantener su objetivo claro y bien definido, cumpliendo con la satisfacción y cuidado de sus clientes, mostrando una imagen pulcra de la empresa guiado por el buen juicio; debe tomar su tiempo y llevar a cabo la tarea de conocer estrategias de la calidad en los servicios orientados al cliente, aprovechando su cartera de clientes logrando no solo ampliarla sino retenerla y fidelizarla, (De Gómez \& De Berrios, 2008). La familiarización de conceptos a los propósitos y objetivos debe ser precisa, por ello es indispensable tener conocimiento de los conceptos de calidad en el servicio, el servicio "es un medio para entregar valor a los clientes, facilitando los resultados que los clientes quieren conseguir sin asumir costos o riesgos específicos" (Van Bon et al., 2008).

Mientras la calidad "representa un proceso de mejora continua, en el cual todas las áreas de la empresa buscan satisfacer las necesidades del cliente o anticiparse a ellas, participando activamente en el desarrollo de los productos o en la prestación de servicios" (Álvarez Gallego, 2006). Y finalmente la calidad en el servicio según Pizzo (2013) es el hábito desarrollado y practicado por una organización para interpretar las necesidades y expectativas de sus clientes y ofrecerles, en consecuencia, un servicio accesible, adecuado, ágil, flexible, útil, oportuno, seguro y confiable, aún bajo situaciones imprevistas o ante errores, de tal manera que el cliente se sienta comprendido, atendido y servido personalmente, con dedicación y eficacia, y sorprendido con mayor valor al esperado proporcionando en consecuencia mayores ingresos y menores costos para la organización. Es aquí donde podemos ver como nacen los engranajes de la seducción mediante la calidad en el servicio.

\section{Servucción}

La Servucción, también conocida como la logística detrás del servicio, tiene siete elementos, que empieza con la razón por la que el servicio en sí nace, es decir la necesidad por la que surge, esta búsqueda de (a) satisfacción, esta se logra conociendo cuál es la necesidad que el servicio que brinda la empresa cubre para el cliente. El segundo elemento es el (b) soporte físico, que es toda la infraestructura que apoya el servicio a brindar, en estos tiempos va más allá del edificio, o activo fijo con el que cuenta la organización, todos los elementos que hacen 
posibles momentos de verdad, por lo que páginas webs, redes sociales, cajeros automáticos, etc, son parte de este elemento. El tercer elemento es el (c) personal de contacto, que lo componen todas las personas que entran en contacto directo con los clientes al momento de prestar el servicio, en los diferentes procesos que pueden hacer parte del servicio o de los distintos servicios que brinda una organización existen al menos dos personas con las que el cliente podría tener contacto; se define también el tipo de personal que siempre tendrá contacto con los clientes, y los que podrían tener o no contacto, definiendo un contacto ocasional, este elemento se convierte en el corazón de la empresa por lo que su capacitación y correcta selección puede ser vital para el desempeño de la organización (De Gómez \& De Berrios, 2008; Descals, Eiglier, \& Langeard, 1989).

El siguiente componente (d) servicio interno está compuesto por todos los demás departamentos y personas que apoyan la prestación del servicio, aquellas personas que cumplen funciones que permiten el desarrollo normal del servicio, si la persona que realiza los pedidos o compras no hace su trabajo eficientemente, los demás departamentos tendrían problemas para desempeñarse, lo que generaría un problema en la prestación del servicio. El quinto elemento es (e) DISEÑO, que define paso a paso la ejecución del servicio, es decir es el flujograma del servicio que permitirá analizar los diferentes procesos, evitar cuellos de botella y obtener el servicio más eficiente posible, consiguiendo minimizar errores.; (f) competencia es el análisis que permite mejorar continuamente mediante el uso del benchmarking, de esta manera, por medio de las mejores prácticas se logra optimizar el uso de los recursos, así como permite conocer lo que sucede en el mercado, conduce hacia nuevas estrategias de comunicación y promoción, buscando incrementar nuestra participación en el mercado. Finalmente (g) innovación, que es clave para garantizar el éxito de un servicio, las empresas dedicadas a brindar servicios también deben contar con departamentos de innovación y desarrollo (I\&D) que busquen la correcta evolución de los mismos para brindarle a los clientes, servicios personalizados (De Gómez \& De Berrios, 2008; Descals et al., 1989)

Un producto es considerado en su mayoría como un bien tangible, para Arellano (2010) el producto que forma parte esencial de las $4 \mathrm{P}$ base de marketing, "implica todo aquello que la empresa producto y entrega para la satisfacción de las necesidades del consumidor o usuario. Esto puede ser un bien, un servicio o una mezcla de ellos.", entonces con esta premisa se puede decir que un producto sea tangible o intangible ayuda a las necesidades del cliente por lo que es importante tener la capacidad perenne de llamar a la lealtad total del cliente con una atención antes y después de la compra.

\section{Conclusión}

No hay duda que la competitividad en el siglo XXI se ha incrementado de manera exponencial, llegando a ver empresas que pese a contar con premisas básicas de servicio o producto se han inclinado a las tendencias de la servuccion y con ello ganar el carisma apreciado por el plano sentimental del cliente.

En el Ecuador los índices de servicio al cliente están por debajo de los niveles de países de primer mundo, según datos estadísticos del Instituto Nacional de Estadísticas y Censos INEC (2014) determinó que entre los servicios públicos y privados un 43,6\% de las empresas obtuvo 
números similares en la medición de sus niveles de atención, resaltando que en las empresas públicas el 91,9\% de las personas reporta una atención deficiente, mientras que en las públicas el $37,4 \%$ de los clientes reportó ese nivel de atención. Se recalca que para los usuarios de las empresas públicas uno de los problemas más graves que afecta la prestación de servicios en el sector público es la corrupción.

Otro estudio realizado por la revista EKOS determinó mediante un índice nacional de satisfacción al cliente que existiría un nivel de satisfacción de 72,4\% a nivel nacional, este estudio es anterior a los datos analizados por el INEC (Borja \& Reyes, 2012). Efectivamente existen muchas empresas que generan y mantienen hábitos de servicio especiales con lo que obtienen la fidelización de sus clientes, pero no todas las empresas lo generan, la servuccion puede ser una herramienta que permita a los diferentes modelos de negocios en la actualidad obtener mejores resultados mediante la mejor comprensión de sus clientes y sus necesidades (De Gómez \& De Berrios, 2008)

Finalmente es importante destacar que los objetivos y metas que se deseen lograr en la organización deben ser orientados al cliente siempre tomando en cuenta todo lo que concierne a su naturaleza; como esta cambia y como se debe adaptar la empresa, se debe buscar la generación las ventajas competitivas como la calidad del servicio (Álvarez Gallego, 2006). La calidad es una característica que debe vivirse en todo lo que compone a la organización logrando fortalecerla y llevarla al próximo nivel. La detección a tiempo de los problemas que pueda tener cualquier organización sobre la calidad de servicio, puede permitir la corrección de problemas y el mejoramiento continuo que es uno de las prácticas más reconocidas y significativas en la calidad; entendiendo entonces que las empresas que están realmente orientadas al servicio, están a la vez comprometidas con la calidad del mismo; identificar entonces los siete elementos que hacen la servucción puede facilitar el proceso de planificación y la ejecución del mismo.

\section{Bibliografía}

Álvarez Gallego, I. (2006). Introducción a la calidad: Aproximación a los sistemas de gestión y herramientas de calidad. Vigo: Ideaspropias, 24.

Arellano, R. (2010). Marketing: Enfoque américa latina: El marketing científico aplicado a latinoamérica. México. Editorial Pearson Educación.

Borja, J., \& Reyes, J. (2012). El sector de supermercados en el ecuador. Recuperado el, 19.

De Gómez, M. Y. B., \& De Berrios, O. G. (2008). La servucción y la calidad en la fabricación del servicio. Visión gerencial(1), 21-32.

Descals, A. M., Eiglier, P., \& Langeard, E. (1989). Servucción: McGraw Hill.

Falconí, J. (2015). Los servicios en el ecuador: Algunos desafíos a corto plazo. Paper presented at the United Nations Conference on Trade an Development, Geneva. http://unctad.org/meetings/en/Presentation/c1mem3_2015_p18_Falconi_en.pdf 
INEC. (2014). Directorio de empresas y establecimientos. Retrieved from http://www.ecuadorencifras.gob.ec/documentos/webinec/Estadisticas_Economicas/DirectorioEmpresas/Empresas_2014/Principales_Resultad os_DIEE_2014.pdf

Lovelock, C. H., Carrion, M. A. S., Huete, L. M., Reynoso, J., \& D'Andrea, G. (2004). Administración de servicios: Pearson Education.

Ordoñez, J. A. (2011). Informe de coyntura económica $n^{o} 7$. Retrieved from http://www.utpl.edu.ec/comunicacion/wp-content/uploads/2012/12/utpl-Informe-decoyuntura-economica-N-7-ano-2011.pdf

Pantouvakis, A., \& Bouranta, N. (2013). The interrelationship between service features, job satisfaction and customer satisfaction: Evidence from the transport sector. The TQM Journal, 25(2), 186-201. doi:doi:10.1108/17542731311299618

Pizzo, M. (2013). Construyendo una definición de calidad en el servicio. Recuperado el, 11.

Telégrafo, E. (2015). El sector servicios genera 1,9 millones de empleos. Retrieved from http://www.eltelegrafo.com.ec/noticias/economia/1/el-sector-servicios-genera-19millones-de-empleos

Van Bon, J., de Jong, A., Kolthof, A., Pieper, M., Tjassing, R., van der Veen, A., \& Verheijen, T. (2008). Estrategia del servicio basada en itil@ v3-guía de gestión (spanish version): Van Haren Publishing. 